\title{
The glucocorticoid receptor is required for stress erythropoiesis
}

\author{
Anton Bauer, ${ }^{1,2}$ Francois Tronche ${ }^{2}$ Oliver Wessely, ${ }^{2,3}$ Christoph Kellendonk, ${ }^{2}$ Holger M. Reichardt ${ }^{2}$ \\ Peter Steinlein, ${ }^{1}$ Günther Schütz, ${ }^{2,4}$ and Hartmut Beug ${ }^{1}$ \\ ${ }^{1}$ Research Institute of Molecular Pathology (IMP), Dr. Bohr-Gasse 7, A-1030 Vienna, Austria; ${ }^{2}$ Molecular Biology of the Cell I, \\ Deutsches Krebsforschungszentrum, Im Neuenheimer Feld 280, D-69120 Heidelberg, Germany
}

The glucocorticoid receptor (GR) coordinates a multitude of physiological responses in vivo. In vitro, glucocorticoids are required for sustained proliferation of erythroid progenitors (ebls). Here, we analyze the impact of the GR on erythropoiesis in vivo, using GR-deficient mice or mice expressing a GR defective for transactivation. In vitro, sustained proliferation of primary ebls requires an intact GR. In vivo, the GR is required for rapid expansion of ebls under stress situations like erythrolysis or hypoxia. A particular, GR-sensitive progenitor could be identified as being responsible for the stress response. Thus, GR-mediated regulation of ebl proliferation is essential for stress erythropoiesis in vivo.

[Key Words: Glucocorticoid receptor; stress erythropoiesis; spleen; targeted mutation; mice]

Received July 28, 1999; revised version accepted September 21, 1999.

Glucocorticoids (GCs) are lipophilic hormones that regulate various physiological responses and developmental processes by binding to and modulating the transcriptional activity of their cognate nuclear receptor (GR) (Beato et al. 1995; Cole et al. 1995; Miller and Tyrrell 1995; Tronche et al. 1998). The GR is widely expressed in vertebrate cells. In its liganded form, the GR modulates transcriptional activation or repression of target genes. Whereas activation occurs by cooperative binding of a GR homodimer to glucocorticoid responsive elements (GREs) in target gene promoters, repression by the GR uses mechanisms independent of DNA binding such as interaction with and inhibition of transcription factors like AP-1 or NF-кB (Beato et al. 1995; Gottlicher et al. 1998).

GR functions are essential for survival. Genetically modified mice lacking the GR die at birth and reveal impaired development of several organs (Cole et al. 1995; F. Tronche unpubl. in prep.). Mice with a targeted mu-

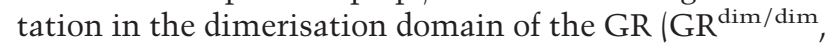
defective for cooperative DNA binding and consequent transactivation but still able to transrepress) show impaired regulation of GRE-dependent genes but survive to adulthood (Reichardt et al. 1998).

A poorly understood aspect of GCs is their potential to stimulate erythropoiesis. In vitro, GCs enhance formation of murine erythroid colonies (Golde et al. 1976) and increase proliferation of erythroid cells in the presence of

\footnotetext{
${ }^{3}$ Present address: Howard Hughes Medical Institute, University of California, Los Angeles (UCLA), Los Angeles, California 90095-1662 USA. ${ }^{4}$ Corresponding author.

E-MAIL g.schuetz@dkfz-heidelberg.de; FAX +49-6221-423470.
}

limiting amounts of erythropoietin (Epo) (Udupa et al. 1986). In humans suffering from certain anemias, GCs can restore normal erythropoiesis (Zito and Lynch 1977; Liang et al. 1994). In addition, pathological changes of GC levels affect erythropoiesis: Morbus Addison, a disease caused by insufficient corticosteroid production, is associated with anemia, whereas increased red blood cell (RBC) count, hemoglobin, and hematocrit values are observed in Cushing's syndrome patients showing elevated GC levels (Miller and Tyrrell 1995).

The best studied systems in which GCs affect erythropoiesis are in vitro cultures of normal erythroblasts from chickens, mice, or humans. In these cells, the GR cooperates with the activated Epo receptor (EpoR) and with c-Kit, the receptor for stem cell factor (SCF), to induce long-term proliferation accompanied by differentiation arrest (Wessely et al. 1997, 1999; Reichardt et al. 1998; von Lindern et al. 1999). This proliferation induction requires the DNA-binding and transactivation functions of the GR (Wessely et al. 1997; Reichardt et al. 1998).

In contrast to these in vitro findings, $\mathrm{GR}^{\text {null } / \mathrm{null}} \mathrm{em}$ bryos or $\mathrm{GR}^{\mathrm{dim} / \mathrm{dim}}$ mice show no obvious defects in normal erythropoiesis. However, because GCs are predominantly released upon stress to maintain homeostasis (Axelrod and Reisine 1984; Miller and Tyrrell 1995; Tronche et al. 1998), it is conceivable that the GR might be required for maximal expansion of a stress-related, GR-responsive erythroid progenitor compartment. Stress erythropoiesis is induced upon blood loss, hemolysis, or impaired erythrocyte function during erythroleukemia and under conditions of oxygen deprivation (e.g., as seen at high altitudes). Several reports are in line with the idea 
that a combination of GCs, SCF, and Epo stimulate stress erythropoiesis, similar to the requirement of this combination of factors for in vitro expansion of immature erythroblasts (Wessely et al. 1997, 1999; von Lindern et al. 1999). For instance, hypophysectomized animals lacking GC release triggered by the hypothalamus-pituitary-adrenal (HPA) axis developed anemia (Lindemann et al. 1969) and showed an impaired erythropoietic response to hypoxic stress (Van Dyke et al. 1954; Means and Dessypris 1993). Furthermore, abrogation of c-Kit activation impairs the stress response to hemolysis (Broudy et al. 1996). Finally, Epo levels are increased in response to hypoxia (Guillemin and Krasnow 1997). Interestingly, stress erythropoiesis mainly occurs in the spleens of mice, whereas bone marrow erythropoiesis is hardly affected (Ou et al. 1980; Broudy et al. 1996).

In this paper we demonstrate that GR function is essential for the expansion of immature erythroid cells during stress erythropoiesis. In vitro, erythroid cells from fetal livers of $G^{\text {null/null }}$ or $\mathrm{GR}^{\mathrm{dim} / \mathrm{dim}}$ mice fail to undergo sustained proliferation in contrast to wild-type cells. Upon hemolysis in vivo, wild-type mice responded with strongly increased numbers of colony-forming units-erythroid (CFU-Es) in their spleens, whereas $\mathrm{GR}^{\mathrm{dim} / \mathrm{dim}}$ mice showed no response. Similarly, rapid adaptation to hypoxic stress by increases in erythrocyte count, hematocrit, and hemoglobin content of peripheral blood was observed in wild-type but not in $\mathrm{GR}^{\mathrm{dim} / \mathrm{dim}}$ mice. GR-dependent expansion upon stress was restricted to a specific erythroid compartment showing a unique combination of surface antigens. Finally, lethally irradiated wild-type mice grafted with fetal liver cells from GR $\mathrm{G}^{\text {null/null }}$ embryos showed similar defects in stress erythropoiesis as $\mathrm{GR}^{\mathrm{dim} / \mathrm{dim}}$ mice, supporting the conclusion that GR activation in erythroid progenitors (ebls) is required for enhanced erythropoiesis in vitro and in vivo.

\section{Results}

Mice lacking the GR die at birth (Cole et al. 1995; Tronche et al. 1998). We therefore used fetal livers after onset of definitive erythropoiesis at E14.5 to compare the proliferative potential of their ebls to those of wild-type mice. Respective fetal liver cell suspensions were cultivated in serum-free medium plus SCF and Epo, together with the synthetic GR agonist dexamethasone (Dex). Ebls from wild-type fetal livers could be maintained in culture for up to 14 days and yielded a 500- to 1000-fold net increase in cell number (Fig. 1A). In similar cultures from $\mathrm{GR}^{\text {null/null }}$ fetal livers (lacking the GR), no outgrowth of ebls could be detected (Fig. 1A). This is similar to wild-type fetal liver cells exposed to the GR antagonist ZK 112.993 (data not shown; Wessely et al. 1997). This proliferation-inducing function of the GR requires its binding to DNA, because fetal liver ebls from $\mathrm{GR}^{\mathrm{dim} / \mathrm{dim}}$ mice (Reichardt et al. 1998) were similarly impaired in proliferation (data not shown). Analysis of cytospin preparations at day 6 of culture (Fig. 1B) re-

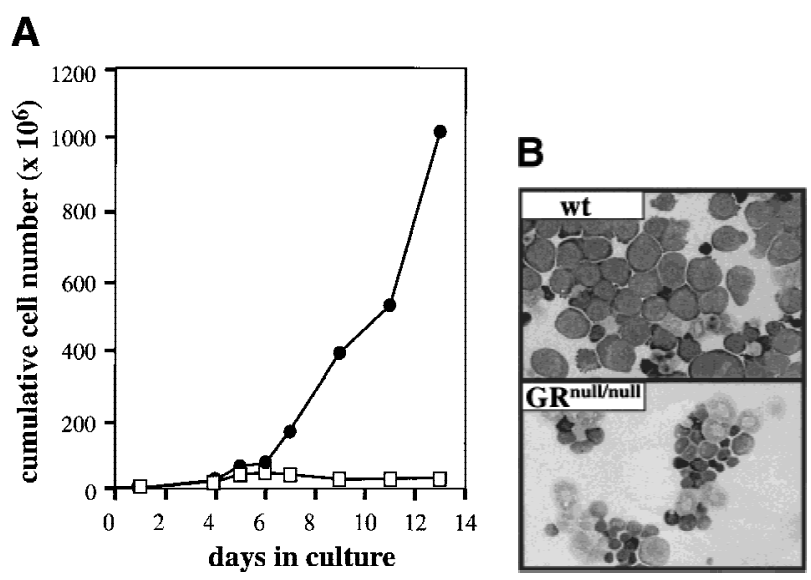

Figure 1. Proliferation of murine ebls in vitro requires ligandactivated GR. Fetal livers were isolated on day 14.5 from wildtype $(\mathrm{wt}, \mathbf{O})$ and $\mathrm{GR}^{\text {null/null }}(\square)$ littermate embryos. Cells were suspended and cultivated in media containing Dex, SCF, and Epo. (A) Cells were counted at daily intervals, and cumulative cell numbers were determined. $(B)$ Aliquots from the cultures were cytocentrifuged onto slides on day 6 and processed for histological staining. Images were taken using a CCD camera and processed with Adobe Photoshop software. Hemoglobin positive cells appear grey to black (Wessely et al. 1997). Note the large ebls in wild-type cultures. This contrasts with the mostly small, highly hemoglobinized reticulocytes/erythrocytes or dead cells and granulocytes occurring in GR $\mathrm{Gull}^{\text {nuln }}$ cultures.

vealed immature, large and weakly hemoglobinized ebls as the predominant cell type in the wild-type cultures. In contrast, the $\mathrm{GR}^{\text {null/null }}$ cultures contained differentiated, hemoglobinized reticulocytes/erythrocytes, some granulocytes, and disintegrated cells. Thus, the GR is required for sustained proliferation of murine ebls in vitro.

To assess the impact of the GR defect in vivo, we used $\mathrm{GR}^{\mathrm{dim} / \mathrm{dim}}$ mice, because they survive to adulthood. When peripheral blood parameters were examined, no signs of anemia or other obvious abnormalities were found in adult $\mathrm{GR}^{\mathrm{dim} / \mathrm{dim}}$ mice kept in a SPF facility under standard conditions. To address the question of whether or not the GR would be important for stress erythropoiesis, we challenged wild-type and $\mathrm{GR}^{\mathrm{dim} / \mathrm{dim}}$ mice either by drug-induced hemolytic anemia or by hypoxia. The mice were then analyzed for typical responses such as enhanced numbers of erythropoietic progenitors in the spleen (Broudy et al. 1996) or changes in peripheral blood parameters such as increased red blood cell counts, hematocrit, or hemoglobin content.

To induce anemia, phenylhydrazine (PHZ) was repeatedly injected into the mice. After 3 days, both anemic wild-type and $\mathrm{GR}^{\mathrm{dim} / \mathrm{dim}}$ mice showed strongly increased GC levels $(26-38 \mu \mathrm{g} / \mathrm{dl})$ as compared with basal levels $(3-7 \mu \mathrm{g} / \mathrm{d} l)$. Spleen cell suspensions prepared from these mice were then seeded into semisolid medium for determination of erythroid colony formation. Compared with untreated controls, we observed a strong increase of CFU-Es in the spleen of anemic wild-type mice. This response was completely absent in anemic $\mathrm{GR}^{\mathrm{dim} / \mathrm{dim}}$ mice (Fig. 2A,B). 

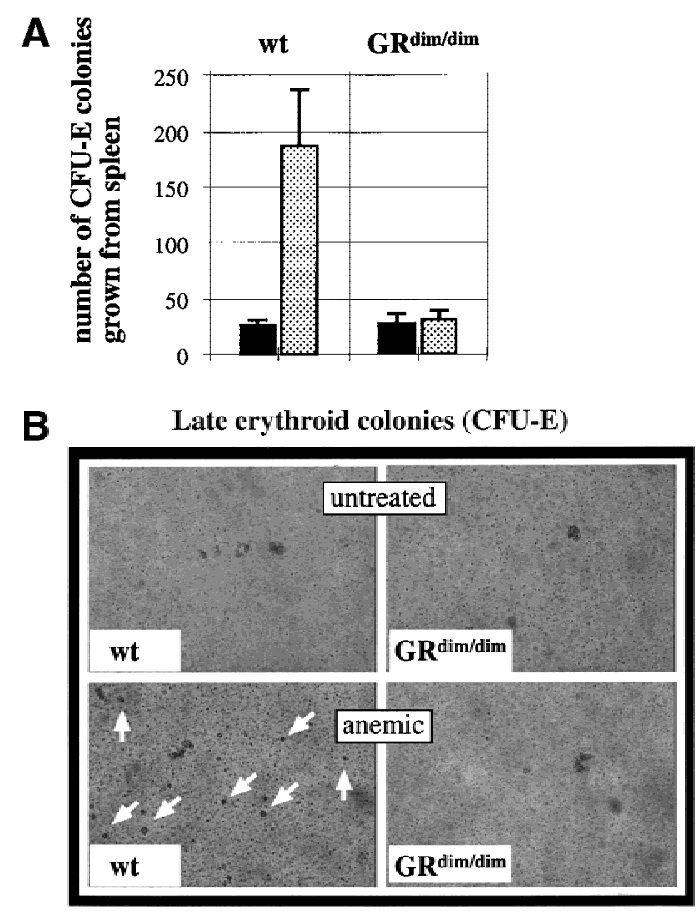

Figure 2. Rapid ebl up-regulation in spleen upon anemia induction requires DNA-binding competent GR. Hemolytic anemia was induced by PHZ injection of adult $\mathrm{GR}^{\mathrm{dim} / \mathrm{dim}}$ mice and their wild-type littermates. On day 3, the spleens of these mice, as well as those from untreated $\mathrm{GR}^{\mathrm{dim} / \mathrm{dim}}$ and wild-type mice (two mice from each group), were isolated, cell suspensions were prepared, and aliquots of equal amounts of cells were seeded in duplicate into semisolid media supporting CFU-E formation. (A) After 2 days the number of CFU-E was counted and mean values and S.D.s determined. (Solid bars) Untreated; (stippled bars) anemic. (B) Pictures of colonies in semisolid medium were taken, and images were processed as described in Fig. 1. The arrows point to CFU-Es. Similar results were obtained in a second, independent experiment (data not shown).

We were then interested in comparing spleen cells from anemic and normal GR ${ }^{\mathrm{dim} / \mathrm{dim}}$ and wild-type mice for their differentiation phenotype, that is, for expression of late and early erythroid markers as well as those shared with more immature progenitors. Cells were triple-stained with antibodies directed against the early hematopoietic markers CD34 and c-Kit (CD117) and the late erythroid-specific marker Ter119, and subjected to FACS analysis (Fig. 3A). The proportion of c-Kit-positive cells was found to be drastically elevated in anemic wildtype mice. In contrast, anemic GR ${ }^{\mathrm{dim} / \mathrm{dim}}$ mice showed an almost unchanged ratio of c-Kit-positive to negative cells (Fig. 3B). In particular, a distinct cell population double-stained by c-Kit plus CD34 antibodies (gated in Fig. 3A) was strongly up-regulated upon anemic stress in wild-type mice but only weakly induced in mutant mice. Interestingly, this cell population coexpressed Ter119 (Fig. 3C), indicating that the cells belong to the erythroid lineage. Thus, expression of DNA-binding competent GR is required for stress (erythrolysis)-induced expansion of a particular type of spleen ebl displaying an un- usual combination of surface markers (coexpression of Ter119 and CD34).

Direct in vivo blood parameters indicative of the ability to adapt to erythropoietic stress (RBC count, hemoglobin content, and hematocrit of peripheral blood) were then measured upon exposing mice to low oxygen. Adult $\mathrm{GR}^{\mathrm{dim} / \mathrm{dim}}$ and wild-type mice were exposed to the same hypoxic conditions ( $11 \%$ oxygen) for 2 days, and peripheral blood samples of these hypoxic animals were analyzed, in comparison to samples from control mice kept under normoxic conditions. As expected, hypoxia induced elevated GC levels in both $\mathrm{GR}^{\mathrm{dim} / \mathrm{dim}}$ and wildtype mice $(22-35 \mu \mathrm{g} / \mathrm{dl})$. When comparing RBC, hemoglobin, and hematocrit in hypoxic versus normoxic wildtype mice, the expected clear increases above normal levels were observed. In contrast, none of these parameters were elevated by hypoxia in the $\mathrm{GR}^{\mathrm{dim} / \mathrm{dim}}$ mice (Fig. 4A). These results were confirmed by measuring CFU-E colony formation by spleen cell suspensions from the same animals, which showed hypoxia-elevated CFU-E numbers in wild-type but not in mutant animals (Fig. 4B).

Finally, we wanted to determine whether or not the impaired response of $\mathrm{GR}^{\mathrm{dim} / \mathrm{dim}}$ mice to hypoxia is due to a cell-autonomous defect in their ebls. To generate mice lacking a functional GR exclusively in their hematopoietic cells, we reconstituted lethally irradiated wildtype mice with $\mathrm{GR}^{\text {null/null }}$ fetal liver suspensions. As controls, similarly irradiated wild-type mice were reconstituted with wild-type fetal liver cells. Ten weeks after reconstitution, the grafted mice were analyzed by maintaining them for 2 days under hypoxic conditions and then evaluating their blood parameters as described above. Wild-type mice grafted with GR ${ }^{\text {null/null }}$ fetal liver cells showed essentially no response to the hypoxic stimulus. In the control mice grafted with wild-type cells, however, blood parameters were clearly increased upon hypoxia induction as compared with normoxic controls (Fig. 5). Thus, GR expression in hematopoietic cells is required for the adaptive response to hypoxia. These data provide further support for the hypothesis that the defect in stress erythropoiesis observed in $\mathrm{GR}^{\mathrm{dim} / \mathrm{dim}}$ mice is intrinsic to ebls lacking a functional GR.

\section{Discussion}

The results presented here constitute the first conclusive proof that nuclear hormone receptors in addition to plasma membrane receptors (such as the EpoR and c-Kit) are essential for aspects of hematopoiesis in vivo. Although circumstantial evidence based on in vitro results pointed to a role of the GR (Chang et al. 1993; Wessely et al. 1997), the estrogen receptor (see von Lindern et al. 1998, and references therein), or the thyroid hormone receptor (see Bauer et al. 1998, and references therein) in erythropoiesis, definitive proof for an important role of nuclear receptors in erythropoiesis in vivo was lacking, because the particular knockout mice failed to show respective phenotypes. 
A
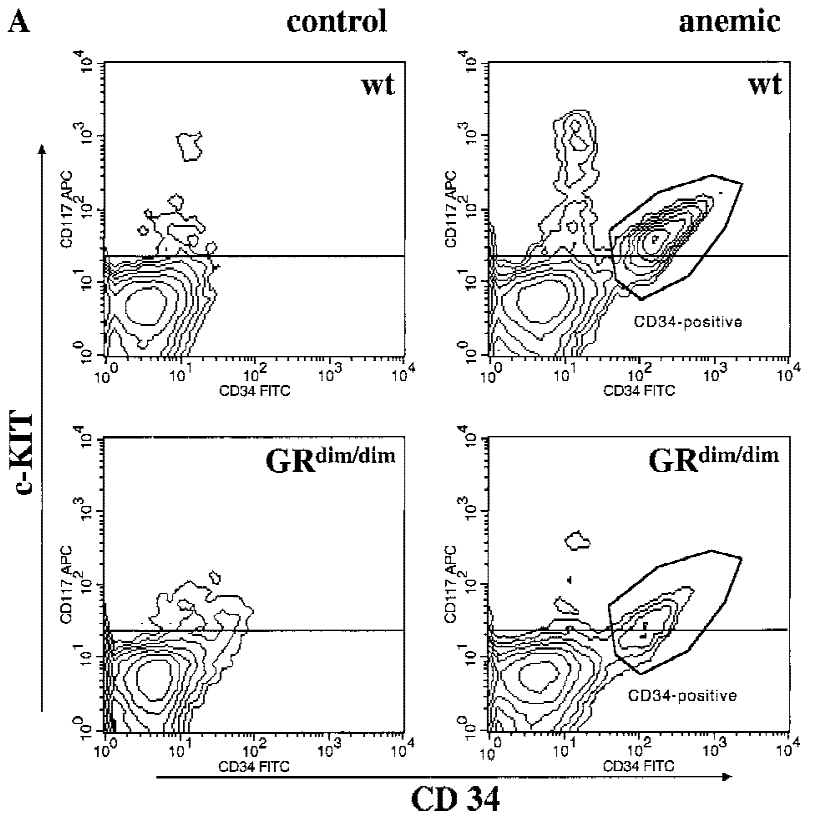

B

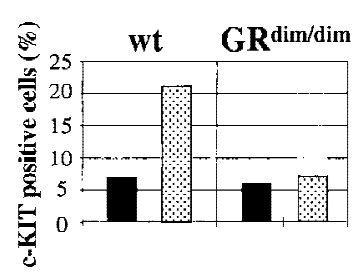

C

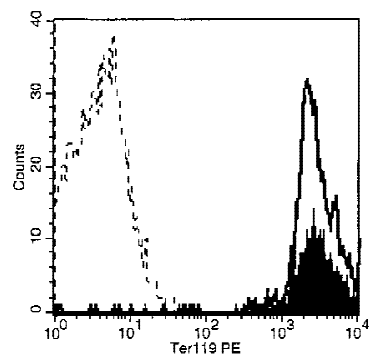

Figure 3. Anemia-induced accumulation of erythroid, c-Kitpositive progenitors in spleen is dependent on DNA-binding competent GR. Aliquots of spleen cell suspensions, prepared as described in Fig. 2, were immunostained with fluorochromelabeled antibodies directed against CD34, c-Kit (CD117), and the erythroid marker Ter119. (A) Viable cells were gated and evaluated by FACS analysis. The result is illustrated as a contour plot for CD34 vs. CD117. (B) The fraction of c-Kit-positive cells (above the horizontal line indicated in $A$ ) was quantitated in untreated (solid bars) and anemic (stippled bars) wild-type and $\mathrm{GR}^{\mathrm{dim} / \mathrm{dim}}$ mice. $(C)$ The outlined, CD117/CD34 double positive cell populations (highly enriched in the anemic wild-type animals; A) were gated and analyzed for expression of Ter119 in wild-type (solid line, filled in white) and GR ${ }^{\mathrm{dim} / \mathrm{dim}}$ mice (solid line, filled in black). The broken line shows background staining in the absence of Ter119 antibody.

Specifically, the GR is required for the rapid expansion of a particular ebl compartment upon induction of erythropoietic stress such as low oxygen or blood loss. Impaired signaling from the membrane receptors c-Kit and EpoR (which cooperate with the GR to induce proliferation of cultured normal chicken, mouse, and human ebl) not only affects stress erythropoiesis but also causes erythropoiesis defects during normal development. Thus, these defects are apparent in nonstressed mice (Chabot et al. 1988; Wu et al. 1995; Broudy 1997). In

contrast, a prominent in vivo role of the GR in hematopoiesis becomes apparent exclusively in stress situations, a situation true also for effects of the GR in other cell types and organs (Tronche et al. 1998). Following stress induction by hemolysis or hypoxia, elevated levels of CFU-Es were detected in spleens of wild-type but not of $\mathrm{GR}^{\mathrm{dim} / \mathrm{dim}}$ mice, suggesting that progenitors related to CFU-Es home to and/or expand in the spleen in a GRdependent manner. A particular, stress (erythrolysis)-induced ebl population was responsible for the GR-dependent up-regulation of ebls. Interestingly, this population expressed an unorthodox combination of surface markers (c-Kit/CD34/Ter119 triple positive). A similar c-Kitpositive "stress population" of ebls was previously predicted (but not shown) to exist (Broudy et al. 1996).

What mechanisms could be responsible for GR effects in stress erythropoiesis? Previous work suggested that the GR modulates the balance of ebl proliferation versus differentiation in culture by directly regulating the hematopoietic cell-specific transcription factors c-Myb (Mucenski et al. 1991; Wessely et al. 1997) and GATA-1 (Pevny et al. 1991; Chang et al. 1993). Further erythroid target genes of the GR in ebls are currently being identified (H. Beug and G. Schütz, unpubl.). Steroids such as GCs also stimulate erythropoiesis indirectly by increasing Epo production in the kidney (Fisher 1998). The molecular basis for this is unclear, because regulatory elements for transcriptional control of Epo expression are only described for the transcription factors HIF and HNF-4 (Galson et al. 1995; Wang and Semenza 1996; Guillemin and Krasnow 1997) but not for the GR. Thus, the impaired stress erythropoiesis observed in GR ${ }^{\mathrm{dim} / \mathrm{dim}}$ mice might be explained by abolishing both direct and indirect stimulatory effects of the GR on erythropoiesis. Nevertheless, the defect observed in wild-type mice grafted with GR ${ }^{\text {null/null }}$ fetal livers emphasizes the contribution of cell-autonomous GR activation in ebls to adaptive responses to hypoxia.

If self-renewal is defined as the prolonged proliferation of progenitors in the apparent absence of differentiation, our findings also challenge the view that the hematopoietic stem cell (HSC) is the only self-renewing cell type in hematopoiesis. Rather, our results suggest an unexpected plasticity of committed progenitors allowing their long-term expansion under particular conditions (e.g., hypoxia in case of erythroblasts). Several problems could arise if the small HSC compartment (Uchida and Weissman 1992; Morrison et al. 1996) would be solely responsible for the drastically increased production of erythrocytes from Epo-responsive progenitors upon erythropoietic stress (Hara and Ogawa 1976; Brewer and Prasad 1993; Lacombe and Mayeux 1998). First, this process might not be fast enough (e.g., completed within a few days) to allow the organism to survive. Second, such a high demand on the HSC compartment would increase the risk of leukemic transformation. Hence, there is an obvious benefit from a mechanism by which committed progenitors closely related to mature erythrocytes undergo sustained proliferation in response to particular, stress-specific, ligand combinations that do not affect 
A
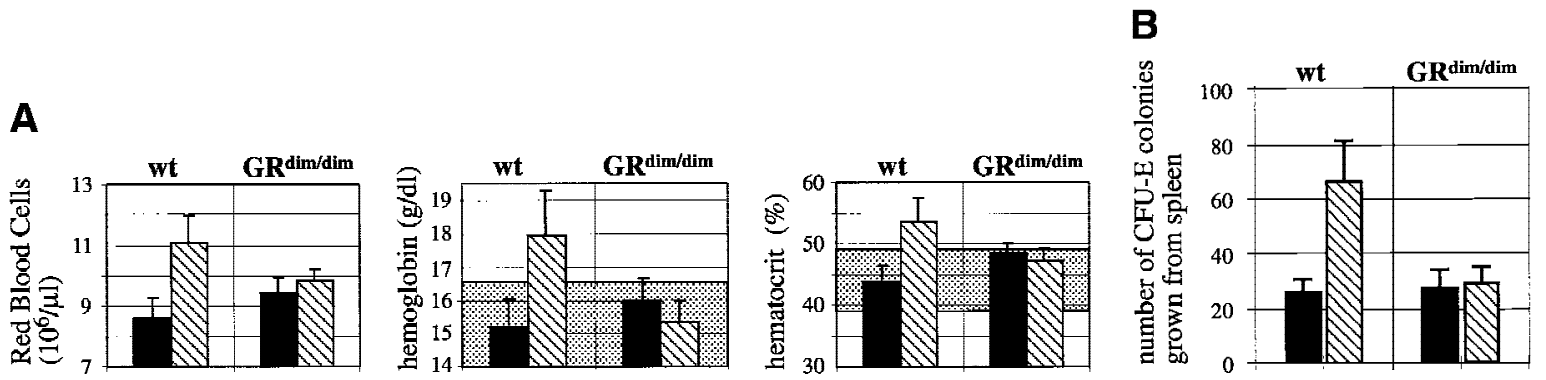

Figure 4. Lack of rapid adaptation to hypoxia in $\mathrm{GR}^{\mathrm{dim} / \mathrm{dim}}$ mice. Adult $\mathrm{GR}^{\mathrm{dim} / \mathrm{dim}}$ and wild-type littermates were subjected to hypoxic conditions $\left(11 \% \mathrm{O}_{2}\right)$ for 2 days. $(A)$ Blood samples from hypoxia-treated mice (hatched bars; four GR ${ }^{\text {dim/dim }}$, six wild-type animals) and untreated animals (black bars, five animals each of $\mathrm{GR}^{\mathrm{dim} / \mathrm{dim}}$ and wild-type) were analyzed for blood parameters by an automated hematometer (Serano 9020). Mean values and S.D.s for RBC counts, hemoglobin concentrations, and hematocrit values were calculated. The range of values determined for hemoglobin and hematocrit values in a large number of normal animals are depicted as dotted areas (Harkness and Wagner 1995). (B) The spleens of hypoxic (three per group) and normoxic mice (two per group) were isolated, cell suspensions were prepared, and aliquots containing equal cell numbers were plated in duplicate in semisolid medium supporting CFU-E formation. After 2 days, the number of CFU-E was counted, and mean values and s.D.s were calculated.

multipotent progenitors or even the HSC. In this context, it is interesting that multipotent progenitors transformed by various nuclear oncogenes (Beug et al. 1995; C. Schulte, H. Beug, and L. Wiedemann, unpubl.) require cooperation with c-Kit for proliferation but grow in GR antagonists, suggesting that glucocorticoids are not required for renewal of these multipotent progenitors in culture (H. Beug, unpubl.).

Finally, our findings also provide a new answer to the old question of how erythroleukemia caused by avian retroviruses expressing receptor tyrosine kinase oncogenes is induced and progresses in the chicken. Many of these retroviruses initially cause only severe anemias in chicks, which only later progress into full-blown leukemias (see Graf and Beug 1978; Beug et al. 1985, and references therein). In this scenario, the initial stress (anemia) caused by the retrovirus might provide the elevation in GCs to stimulate the GR, which the RTK oncoprotein requires for induction of leukemic self-renewal. This speculation is consistent with the fact that retroviral capture of the thyroid hormone receptor and its oncogenic activation to yield v-ErbA abolishes the requirement for an activated GR (Bauer et al. 1997). Thus, it is not surprising that v-ErbA drastically increases leukemogenic potential (see Graf and Beug 1978, and references therein).

\section{Materials and methods}

\section{Isolation of fetal livers}

Heterozygous $\mathrm{GR}^{+/ \text {null }}$ mice were mated, and embryos isolated on day E-14.5. Fetal livers were isolated and individually suspended in PBS by repeated, gentle pipetting. Aliquots were assayed for the outgrowth of ebls or used for bone marrow reconstitution (see below). Embryonic body parts were used for genotyping by Southern blot (Tronche et al. 1999).

\section{FACS analysis}

Aliquots of fetal liver or spleen cell suspensions were incubated with Fc Block (Pharmingen, CA) in PBS plus 1\% BSA. They were then stained with directly labeled antibodies [combinations of phycoerythrin (PE)-, fluorescein isothiocyanate (FITC)-, and allophycocyanin (APC)-labeled antibodies; all from Pharmingen] against mouse c-Kit, Ter119, CD71, CD34, GR-1, and Mac-1. After $30 \mathrm{~min}$ on ice, cells were washed two times and resuspended in PBS plus 1\% BSA, containing propidium iodine as vital stain. Stained cell preparations were analyzed using a FACS-Vantage (Becton Dickinson).

\section{Proliferation kinetics}

Fetal liver cell suspensions were seeded in modified CFU-E medium (Beug et al. 1985) or serum-free medium (StemPro34, Life Technologies) supplemented with $100 \mathrm{ng} / \mathrm{ml}$ murine SCF (R\&D), 2 U/ml human recombinant Epo (CILAG AG), IGF-I (40 $\mathrm{ng} / \mathrm{ml}$; Sigma), and the GR agonist Dex ( $1 \mu \mathrm{M}$; Sigma). The GR antagonist ZK 112.993 (Wessely et al. 1997) was used at a concentration of $3 \times 10^{-6} \mathrm{M}$. Erythroblast cultures were maintained at a density between $2 \times 10^{6}$ and $4 \times 10^{6}$ cells $/ \mathrm{ml}$ by daily medium changes plus readdition of fresh factors with or without appropriate dilution. Growth kinetics were determined by daily counting in an electronic cell counter (CASY-1, Schärfe-System, Germany) and cumulative cell numbers calculated.

\section{Analysis of fetal liver cultures by cell morphology} and histochemical staining

Cells in liquid cultures were cytocentrifuged onto slides and analysed by combined histological/histochemical staining (Wessely et al. 1997).

\section{Genotyping of genetically modified mice}

$\mathrm{GR}^{\mathrm{dim} / \mathrm{dim}}$ or $\mathrm{GR}^{\text {null/null }}$ mice were genotyped by PCR (Reichardt et al. 1998) or by Southern blot analysis, respectively (Tronche et al. 1999).

\section{PHZ treatment of mice and spleen cell colony assay}

Adult mice were injected intraperitoneally with $60 \mathrm{mg} / \mathrm{kg}$ PHZ on day 0 and day 1 as described (Broudy et al. 1996). On day 3, blood samples were collected by heart puncture, and spleen cell suspensions prepared by squeezing the spleen through a $70-\mu \mathrm{m}$ 

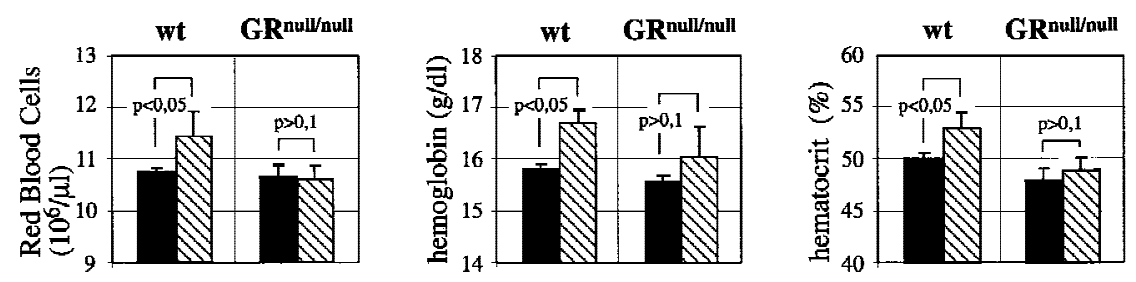

Figure 5. GR expression in ebls is essential for erythropoietic stress response. Adult C57BL/6 mice were irradiated with 9.5 Gy and subsequently grafted with fetal liver suspensions prepared from either GR $\mathrm{Gull}^{\text {null }}$ or wild-type littermate embryos. Ten weeks after grafting, the wild-type mice reconstituted with wild-type or $\mathrm{GR}^{\text {null/null }}$ fetal liver cells were stressed by hypoxia and analyzed for blood parameters as described in the legend to Fig. 4 (total of four mice per group, two independent experiments) (hatched bars). As a control, mice grafted with wild-type or GR ${ }^{\text {null/null }}$ fetal livers and kept under normoxic conditions (black bars) were analyzed. The changes were evaluated for their statistical significance by the Wilcoxon rank sum test (increase regarded as significant when $P<0.05$ ).

cell strainer followed by two washes with cold PBS. Cells were resuspended in StemPro34 medium (Life Technologies) and then seeded at various concentrations $\left(2 \times 10^{5}-2 \times 10^{6}\right.$ cells $/$ well) into methocel containing factor combinations in four-well dishes. Aliquots of cells were also subjected to FACS analysis (see above). For evaluation of CFU-E, MethoCult 3236 was supplemented with human recombinant Epo 15 units; CILAG AG, Schaffhausen, CH), $100 \mathrm{ng} / \mathrm{ml}$ murine SCF (R\&D), IGF-I (40 ng/ml; Sigma), and LDL (40 $\mu \mathrm{g} / \mathrm{ml}$; Sigma), and small, compact colonies were counted on day 2 .

\section{Reconstitution of lethally irradiated mice}

Three-month old C57BL/6 mice were lethally irradiated with 9.5 Gy and grafted by injecting E14.5 fetal liver suspensions in PBS (see above) into the tail vein. Ten weeks after grafting, the mice were analyzed for their response to hypoxia.

\section{Hypoxic stimulation of mice}

$\mathrm{GR}^{\mathrm{dim} / \mathrm{dim}}$ mice and wild-type controls, or irradiated mice reconstituted with fetal liver cells of GR Gull/null $^{\text {nald }}$ and-type embryos, respectively, were kept together in one cage and supplied with air containing $11 \%$ oxygen (complemented with nitrogen; Messer-Griesheim, Germany). GR ${ }^{\mathrm{dim} / \mathrm{dim}}$ and controls were challenged for 2 days with $11 \%$ oxygen. For grafted mice, oxygen was reduced to $8 \%$ on day 2 . After 2 days, blood parameters from all mice were analyzed. For GR ${ }^{\mathrm{dim} / \mathrm{dim}}$ mice and their controls, spleen CFU-Es were also evaluated (see above).

\section{Analysis of blood values}

Blood was collected either by heart puncture of anesthetized mice or tail phlebotomy with EDTA-treated syringes or tubes. To determine RBC, hematocrit, and hemoglobin values, $40 \mu \mathrm{l}$ of blood were analyzed using an automated hematometer (Serano 9020).

\section{Acknowledgments}

We thank Marieke von Lindern for helpful discussions and comments, W. Rittgen for statistical interpretation of the data, Zahir Abasi and Mehtap Özkan for access to, and help with, the hematometer, and Katrin Anlag, Gabi Stengl, Heike Glaser, and Karin Paiha for expert technical assistance. This work was supported by a EU Training and Mobility of Researchers network grant (ERBFMRXCT980197) to GS, HB, and AB, by the Austrian grant agency Fonds Zur Förderung der Wissenschaftlichen Forschung (SFB F006), the Deutsche Forschungsgemeinschagt grant
(SFB 405/A6), and by the FFF Austria (Forschungsförderungsfonds der gewerblichen Wirtschaft).

The publication costs of this article were defrayed in part by payment of page charges. This article must therefore be hereby marked "advertisement" in accordance with 18 USC section 1734 solely to indicate this fact.

\section{References}

Axelrod, J. and T.D. Reisine. 1984. Stress hormones: Their interaction and regulation. Science 224: 452-459.

Bauer, A., E. Ulrich, M. Andersson, H. Beug, and M. von Lindern. 1997. Mechanism of transformation by v-ErbA: Replacement of steroid hormone receptor function in self-renewal induction. Oncogene 15: 701-715.

Bauer, A., W. Mikulits, G. Lagger, G. Stengl, G. Brosch, and H. Beug. 1998. The thyroid hormone receptor functions as a ligand-operated developmental switch between proliferation and differentiation of erythroid progenitors. EMBO $I$. 17: 4291-4303.

Beato, M., P. Herrlich, and G. Schütz. 1995. Steroid hormone receptors: Many actors in search of a plot. Cell 83: 851-857.

Beug, H., M.J. Hayman, T. Graf, S.H. Benedict, A.M. Wallbank, and P.K. Vogt. 1985. S13, a rapidly oncogenic replicationdefective avian retrovirus. Virology 145: 141-153.

Beug, H., R. Dahl, P. Steinlein, S. Meyer, E.M. Deiner, and M.J. Hayman. 1995. In vitro growth of factor-dependent multipotential hematopoietic cells is induced by the nuclear oncoprotein v-Ski. Oncogene 11: 59-72.

Brewer, G.J. and A.S. Prasad. 1993. Biochemistry and function of the erythron. In Hematology: Clinical and laboratory practice (ed. R.L. Bick), pp. 185-202. Mosby-Year Book, Inc., St. Louis, MO.

Broudy, V.C. 1997. Stem cell factor and hematopoiesis. Blood 90: $1345-1364$.

Broudy, V.C., N.L. Lin, G.V. Priestley, K. Nocka, and N.S. Wolf. 1996. Interaction of stem cell factor and its receptor c-kit mediates lodgment and acute expansion of hematopoietic cells in the murine spleen. Blood 88: 75-81.

Chabot, B., D.A. Stephenson, V.M. Chapman, P. Besmer, and A. Bernstein. 1988. The proto-oncogene c-kit encoding a transmembrane tyrosine kinase receptor maps to the mouse $\mathrm{W}$ locus. Nature 335: 88-89.

Chang, T.J., B.M. Scher, S. Waxman, and W. Scher. 1993. Inhibition of mouse GATA-1 function by the glucocorticoid receptor: Possible mechanism of steroid inhibition of erythroleukemia cell differentiation. Mol. Endocrinol. 7: 528-542.

Cole, P.J., J.A. Blendy, A.P. Monaghan, K. Kriegelstein, W. Schmid, A. Aguzzi, G. Fantuzzi, E. Hummler, K. Unsicker, 
and G. Schütz. 1995. Targeted disruption of the glucocorticoid receptor gene blocks adrenergic chromaffin cell development and severely retards lung maturation. Genes \& Dev. 9: $1608-1621$.

Fisher, J.W. 1998. A quest for erythropoietin over nine decades. Annu. Rev. Pharmacol. Toxicol. 38: 1-20.

Galson, D.L., T. Tsuchiya, D.S. Tendler, L.E. Huang, Y. Ren, T. Ogura, and H.F. Bunn. 1995. The orphan receptor hepatic nuclear factor 4 functions as a transcriptional activator for tissue-specific and hypoxia-specific erythropoietin gene expression and is antagonized by EAR3/COUP-TF1. Mol. Cell. Biol. 15: 2135-2144.

Golde, D.W., N. Bersch, and M.J. Cline. 1976. Potentiation of erythropoiesis in vitro by dexamethasone. J. Clin. Invest. 57: 57-62.

Gottlicher, M., S. Heck, and P. Herrlich. 1998. Transcriptional cross-talk, the second mode of steroid hormone receptor action. J. Mol. Med. 76: 480-489.

Graf, T. and H. Beug. 1978. Avian leukemia viruses: Interaction with their target cells in vivo and in vitro. Biochim. Biophys. Acta 516: 269-299.

Guillemin, K. and M.A. Krasnow. 1997. The hypoxic response: Huffing and HIFing. Cell 89: 9-12.

Hara, H. and M. Ogawa. 1976. Erthropoietic precursors in mice with phenylhydrazine-induced anemia. Am. I. Hematol. 1: 453-458.

Harkness, J.E. and J.E. Wagner. 1995. The biology and medicine of rabbits and rodents. Williams \& Wilkins, Baltimore, MD.

Lacombe, C. and P. Mayeux. 1998. Biology of erythropoietin. Haematologica 83: 724-732.

Liang, R., T.K. Chan, and D. Todd. 1994. Childhood acute lymphoblastic leukaemia and aplastic anaemia. Leuk. Lymphoma 13: 411-415.

Lindemann, R., O. Trygstad, and S. Halvorsen. 1969. Pituitary control of erythropoiesis. Scand. J. Haematol. 6: 77-86.

Means, R.T.J. and E.N. Dessypris. 1993. The anemias of chronic disease, renal failure, and endocrine disorders. In Hematology: Clinical and laboratory practice (ed. R.L. Bick), pp. 419429. Mosby-Year Book, Inc., St. Louis, MO.

Miller, W.L. and J.B. Tyrrell. 1995. The Adrenal Cortex. In Endocrinology and metabolism (ed. P. Fehlig, J.D. Baxter, and L.A. Frohman), pp. 555-711. McGraw-Hill, Inc., New York, NY.

Morrison, S.J., A.M. Wandycz, K. Akashi, A. Globerson, and I.L. Weissman. 1996. The aging of hematopoietic stem cells. Nat. Med. 2: 1011-1016.

Mucenski, M.L., K. McLain, A.B. Kier, S.H. Swerdlow, C.M. Schreiner, T.A. Miller, D.W. Pietryga, W.J. Scott Jr., and S.S. Potter. 1991. A functional c-myb gene is required for normal murine fetal hepatic hematopoiesis. Cell 65: 677-689.

Ou, L.C., D. Kim, W.M. Layton Jr., and R.P. Smith. 1980. Splenic erythropoiesis in polycythemic response of the rat to high-altitude exposure. J. Appl. Physiol. 48: 857-861.

Pevny, L., M.C. Simon, E. Robertson, W.H. Klein, S.F. Tsai, V. D'Agati, S.H. Orkin, and F. Costantini. 1991. Erythroid differentiation in chimaeric mice blocked by a targeted mutation in the gene for transcription factor GATA-1. Nature 349: 257-260.

Reichardt, H.M., K.H. Kaestner, J. Tuckermann, O. Kretz, O. Wessely, R. Bock, P. Gass, W. Schmid, P. Herrlich, P. Angel, and G. Schütz. 1998. DNA binding of the glucocorticoid receptor is not essential for survival. Cell 93: 531-541.

Tronche, F., C. Kellendonk, H.M. Reichardt, and G. Schütz. 1998. Genetic dissection of glucocorticoid receptor function in mice. Curr. Opin. Genet. Dev. 8: 532-538.

Tronche, F., C. Kellendonk, O. Kretz, P. Gass, K. Anlag, O.P. C.,
R. Bock, R. Klein, and G. Schütz. 1999. Disruption of the glucocorticoid receptor gene in the nervous system results in reduced anxiety. Nat. Genet. 23: 99-103.

Uchida, N. and I.L. Weissman. 1992. Searching for hematopoietic stem cells: Evidence that Thy-1.1lo Lin- Sca-1+ cells are the only stem cells in C57BL/Ka-Thy-1.1 bone marrow. J. Exp. Med. 175: 175-184.

Udupa, K.B., H.M. Crabtree, and D.A. Lipschitz. 1986. In vitro culture of proerythroblasts: Characterization of proliferative response to erythropoietin and steroids. Br. J. Haematol. 62: $705-714$

Van Dyke, D.C., A.N. Contopoulos, B.S. Williams, M.E. Simpson, J.H. Lawrence, and H.M. Evans. 1954. Hormonal factors influencing erythropoiesis. Acta Haemat. 11: 203-222.

von Lindern, M., L. Boer, O. Wessely, M. Parker, and H. Beug. 1998. The transactivation domain AF-2 but not the DNAbinding domain of the estrogen receptor is required to inhibit differentiation of avian erythroid progenitors. Mol. Endocrinol. 12: 263-277.

von Lindern, M., W. Zauner, G. Mellitzer, P. Steinlein, G. Fritsch, K. Huber, B. Löwenberg, and H. Beug. 1999. The glucocorticoid receptor cooperates with the erythropoietin receptor and c-Kit to enhance and sustain proliferation of erythroid progenitor in vitro. Blood 94: 550-559.

Wang, G.L. and G.L. Semenza. 1996. Molecular basis of hypoxia-induced erythropoietin expression. Curr. Opin. Hematol. 3: 156-162.

Wessely, O., E.M. Deiner, H. Beug, and M. von Lindern. 1997. The glucocorticoid receptor is a key regulator of the decision between self-renewal and differentiation in erythroid progenitors. EMBO J. 16: 267-280.

Wessely, O., A. Bauer, C.T. Quang, E.M. Deiner, M. von Lindern, G. Mellitzer, P. Steinlein, J. Ghysdael, and H. Beug. 1999. A novel way to induce erythroid progenitor self renewal: Cooperation of c-Kit with the erythropoietin receptor. Biol. Chem. 380: 187-202.

Wu, H., X. Liu, R. Jaenisch, and H.F. Lodish. 1995. Generation of committed erythroid BFU-E and CFU-E progenitors does not require erythropoietin or the erythropoietin receptor. Cell 83: 59-67.

Zito, G.E. and E.C. Lynch. 1977. Prednisone-responsive congenital erythroid hypoplasia. J. Am. Med. Assoc. 237: 991-992. 


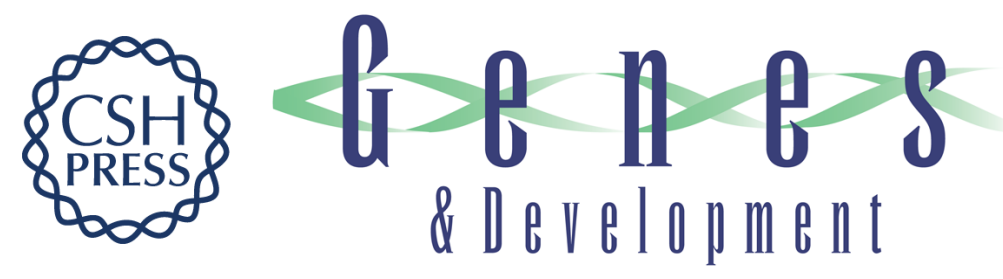

\section{The glucocorticoid receptor is required for stress erythropoiesis}

Anton Bauer, Francois Tronche, Oliver Wessely, et al.

Genes Dev. 1999, 13:

References This article cites 37 articles, 10 of which can be accessed free at: http://genesdev.cshlp.org/content/13/22/2996.full.html\#ref-list-1

License

Email Alerting

Receive free email alerts when new articles cite this article - sign up in the box at the top Service right corner of the article or click here.

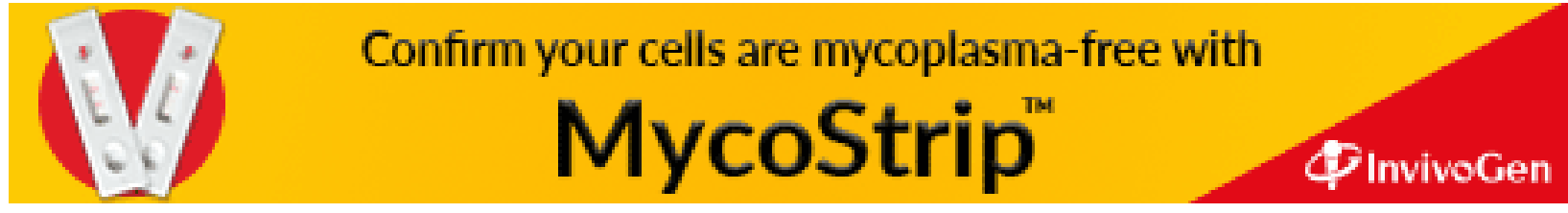

